\title{
Research on Dynamic Characteristics of Trench Type Bidirectional IGBT
}

\author{
Jia Qiang Xie ${ }^{1, a}$, Yong Gao ${ }^{2, b}$, Yuan Yang ${ }^{3, c}$ and Li Ma ${ }^{4, d}$ \\ 1,2,3,4 School of Xi'an University of Technology, Shaanxi 710048, China; \\ A gaoy@xaut.edu.cn, b425571663@qq.com, c yangyuan@xaut.edu.cn ${ }^{\mathrm{d}}$ mali@xaut.edu.cn
}

Keywords: Bidirectional IGBT, Dynamic characteristics.

\begin{abstract}
To improve the switching characteristics of conventional structure IGBT, a new trench type bidirectional insulated gate bipolar transistor (IGBT) is proposed. The main feature of this structure is introducing a cell in collector of conventional trench IGBT. The new type IGBT reduce both turn-on and turn-off losses because double-gate IGBT can accelerate carrier extraction speed. By building the device simulation DC/AC circuit of dynamic characteristics, the turn-on time is $0.12 \mu$ s and turn-off time is 5.1ns. Compared with conventional IGBT, the new type IGBT's turn-on and turn-off loss have a great reduce.
\end{abstract}

\section{Introduction}

The power semiconductor devices are widely used in switching mode power supply circuits, such as motor control of electric and hybrid vehicle (EV/HEV), smart grid network, etc. IGBT is almost the most popular power component switch in the voltage range from $400 \mathrm{~V}$ to $4.5 \mathrm{kV}^{[1]}$. Nowadays the improvements in the performance of the IGBT have been mainly based on the following technology: 1) the field stop layer, 2) the trench gate, 3) the injection enhancement effect, 4) the super junction. These mainstream technologies, to some degree, could offer an excellent compromise between the on-state voltage drop and the turn-off switching loss. Nevertheless, the above-mentioned methods may reach a virtual limit in the field of the matrix converter requiring voltage and current switches ${ }^{[2-5]}$. This paper aimed to explore the feasibility and advantage of the symmetric double-gate IGBT, which can be an alternative method for the monolithically integrated bidirectional switch device.

\section{Device structure and working principle}

A conventional trench type IGBT is shown in Fig.1 (a). Trench type bidirectional IGBT is shown in Fig.1 (b). In order to reflect the advantages of the trench type bidirectional IGBT characteristics, both the conventional IGBT and bidirectional IGBT owned the same structure size. The structural parameters of the two devices are shown in Table 1.The gate oxide layer using $\mathrm{SiO}_{2}$ with the thickness of $0.1 \mu \mathrm{m}$. The total thickness of the device is $395 \mu \mathrm{m}$ with the width of $20 \mu \mathrm{m}$. Electrodes are made of aluminum material.
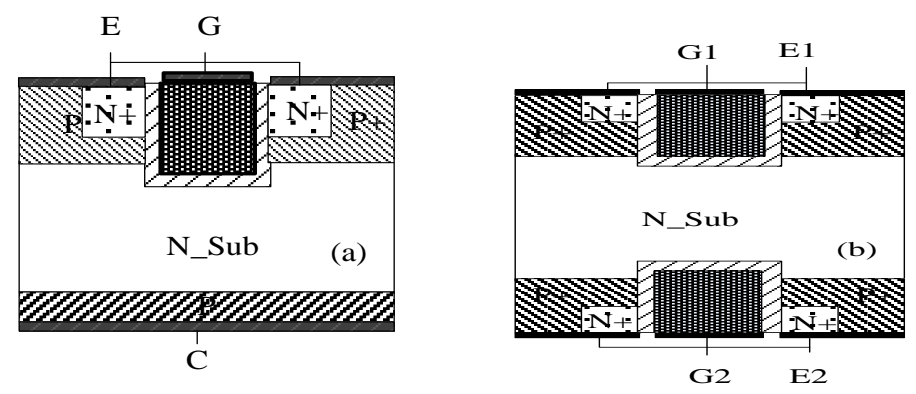

Fig.1 Conventional trench type IGBT(a) and trench type bidirectional IGBT (b) Structures 
Table 1 The structure parameters of trench type bidirectional IGBT and conventional trench type IGBT

\begin{tabular}{|c|c|c|c|c|}
\hline & Doping $\left(\mathrm{cm}^{-3}\right)$ & depth $(\mu \mathrm{m})$ & width $(\mu \mathrm{m})$ & dopant \\
\hline substrate & $3 \times 10^{13}$ & 395 & 20 & $\mathrm{P}$ \\
\hline $\mathrm{N}+$ & $1 \times 10^{20}$ & 1.5 & 1.9 & $\mathrm{P}$ \\
\hline $\mathrm{P}+$ & $2 \times 10^{18}$ & 3.5 & 8 & $\mathrm{~B}$ \\
\hline Poly-Si & $1 \times 10^{20}$ & 4 & 4 & $\mathrm{P}$ \\
\hline
\end{tabular}

There are some different between trench type bidirectional IGBT and conventional trench type IGBT. The electrodes gate, collector and emitter of conventional trench type IGBT is named G, C and E. As shown in Fig.1 (a). Fig.1 (b) shows the trench type bidirectional IGBT have two gate electrodes G1, G2. The other two electrodes named E1, E2.

There are two working statuses in the AC circuit according to the working principle of the device. One is when $\mathrm{V}_{\mathrm{G} 2}=0 ; \mathrm{V}_{\mathrm{E} 1}=0, \mathrm{~V}_{\mathrm{E} 2}>0, \mathrm{~V}_{\mathrm{G} 1}>0 . \mathrm{V}_{\mathrm{E} 1}, \mathrm{~V}_{\mathrm{E} 2}, \mathrm{~V}_{\mathrm{G} 1}$, respectively, as the emitter, collector and gate control the switching characteristics of the device. Another is when $V_{\mathrm{G} 1}=0 ; \mathrm{V}_{\mathrm{E} 2}=0, \mathrm{~V}_{\mathrm{E} 1}>0$, $\mathrm{V}_{\mathrm{G} 2}>0$. $\mathrm{V}_{\mathrm{E} 2}, \mathrm{~V}_{\mathrm{E} 1}, \mathrm{~V}_{\mathrm{G} 2}$, respectively, as the emitter, collector and gate control the switching characteristics of the device. In the states 1 when $0 \mathrm{~V}<\mathrm{V}_{\mathrm{G} 1 \mathrm{E} 1}<\mathrm{V}_{\text {th }}$, the device turn-off. The two sides of the $\mathrm{G} 1$ gradually formed an inversion layer when $\mathrm{V}_{\mathrm{G} 1 \mathrm{E} 1}>\mathrm{V}_{\text {th }}$. Meanwhile, forward voltage make collector E2 hole inject into the substrate region. Then the device conducted. State2 have the same working principle with state ${ }^{[6.7]}$.

\section{Simulation results and analysis}

DC circuit test results and analysis. In the trench type bidirectional IGBT DC circuit test, V2 is a $15 \mathrm{~V}$ pulse signal applied to the gate G2, as shown in Table 2.

Table 2 Pulse signal of $\mathrm{V}_{2}$

\begin{tabular}{|l|c|}
\hline Time(s) & Voltage $(\mathrm{V})$ \\
\hline 0 & 0 \\
\hline $1 \times 10^{-8}$ & 0 \\
\hline $3 \times 10^{-8}$ & 15 \\
\hline $1.003 \times 10^{-5}$ & 15 \\
\hline $1.005 \times 10^{-5}$ & 0 \\
\hline $2 \times 10^{-5}$ & 0 \\
\hline
\end{tabular}

Trench type bidirectional IGBT structure is very special. The double gate structure determines the presence of a plurality of internal resistance inductance capacitance of the device after conducting $^{[8-10]}$. We get the dynamic characteristics curve of the trench type bidirectional IGBT through simulation as Figure 2 shows. Figure 3 is a simulation waveform of the pulse signal V2 applied to the gate G2. It can be directly observed trench type bidirectional IGBT turn-off voltage and current varies with the voltage on the gate G2.

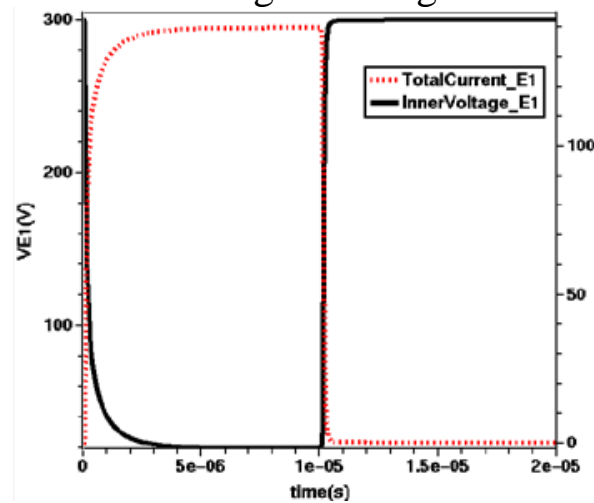

Fig.2 DC dynamic characteristic curve

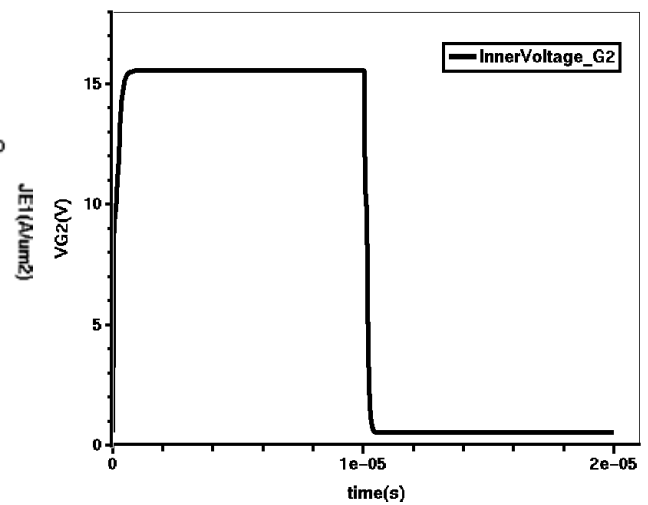

Fig.3 The simulation waveform of V2 
Figures 2 and Figures 3 show the trench type bidirectional IGBT switching characteristics. When the forward voltage of trench type bidirectional IGBT $\mathrm{V}_{\mathrm{G} 2}$ increased from $0 \mathrm{~V}$ to $15 \mathrm{~V}$ at $3 \times 10^{-8} \mathrm{~s}$, both sides of the gate G2 formed on a conductive channel, E1 emitter gradually emerge the current at 6.075 $\times 10^{-8} \mathrm{~s}$; when $\mathrm{V}_{\mathrm{G} 2}=15 \mathrm{~V}, \mathrm{I}_{\mathrm{E} 1}$ shows a stable value and $\mathrm{V}_{\mathrm{E} 1}$ declined from $300 \mathrm{~V}$ to a little value. When $\mathrm{V}_{\mathrm{G} 2}$ declined from $15 \mathrm{~V}$ down to $0 \mathrm{~V}$ at $1.005 \times 10^{-5} \mathrm{~s}$, $\mathrm{I}_{\mathrm{E} 1}$ declined to a minimum value with $\mathrm{V}_{\mathrm{G} 2}$ declining. The time from $\mathrm{V}_{\mathrm{G} 2}$ falling to the collector current begins to falling last almost $0 \mathrm{~s}$. Then $\mathrm{V}_{\mathrm{E} 1}$ returned to $300 \mathrm{~V}$. According to the definition of trench type bidirectional IGBT turn on-time and turn-off time, after the final calculation, the trench type bidirectional IGBT turn-on time is $0.5593 \mu \mathrm{s}$, off-time is $0.1127 \mu \mathrm{s}$. It shows that trench type bidirectional IGBT has a high turn-on and turn-off speed, especially in turn-off speed.

AC circuit test results and analysis. We make a test in $A C$ circuits when $V_{E 2}=0$. The pulse signal in $\mathrm{G} 1$ and $\mathrm{G} 2$ controlled the device conduction and shutdown. There is a $\pm 300 \mathrm{~V}$ pulse signal applied to E1electrode. V3 is a pulse signal applied to the E1 side, as shown in Table 3. V2 is a 15V pulse signal applied to G2, as shown in Table 2. When G2 electrode is conduction, $V_{\mathrm{E} 1}=-300 \mathrm{~V}$ as the collector. Before G2 shutdown, G1 is opening and controls the conduction and shutdown of the device. $\mathrm{V}_{\mathrm{E} 1}=-300 \mathrm{~V}$ as the emitter of the device. $\mathrm{V} 1$ is the pulse signal applied to the gate $\mathrm{G} 1$ as shown in Table 3.

Table 3 Pulse signal of V1

\begin{tabular}{|c|c|}
\hline Time(s) & Voltage(V) \\
\hline 0 & 0 \\
\hline $1.0028 \times 10^{-5}$ & 15 \\
\hline $1.0048 \times 10^{-5}$ & 15 \\
\hline $2 \times 10^{-5}$ & 0 \\
\hline
\end{tabular}

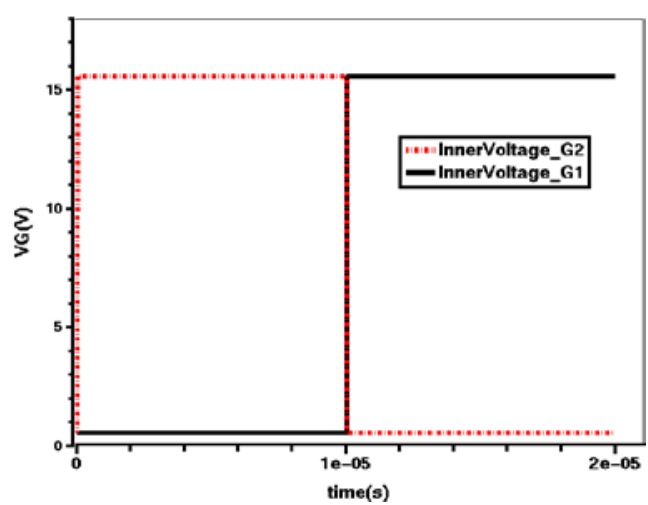

Table 4 Pulse signal of V3

\begin{tabular}{|c|c|}
\hline Time(s) & Voltage(V) \\
\hline 0 & 300 \\
\hline $1.0048 \times 10^{-5}$ & 300 \\
\hline $1.0068 \times 10^{-5}$ & -300 \\
\hline $2 \times 10^{-5}$ & -300 \\
\hline
\end{tabular}

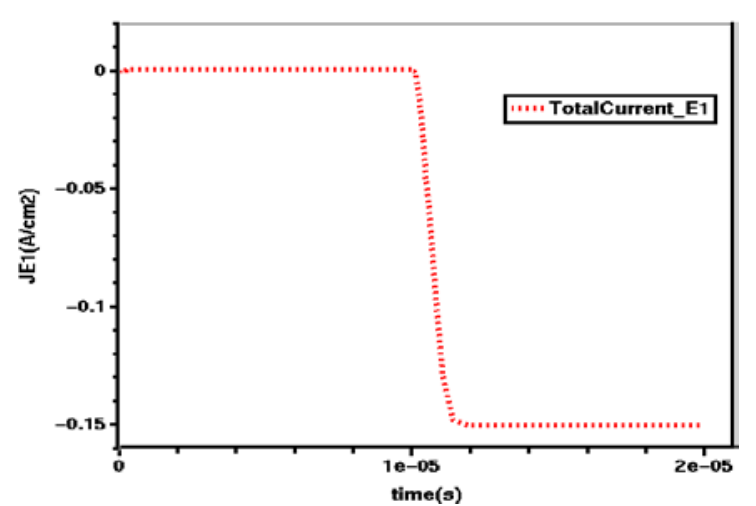

Fig.4 The simulation waveform of V1 and V2 Fig.5 Current dynamic characteristic curve

Trench type bidirectional IGBT V1 and V2 pulse signal is shown in Figure 4. It can be seen from Figure. 4 that $\mathrm{V}_{\mathrm{G} 1}$ reach peak before $\mathrm{V}_{\mathrm{G} 2}$ declined. As table 4 shows, at the peak of the $\mathrm{G} 1$ electrode $\mathrm{V}_{\mathrm{E} 1}$ convert from $-300 \mathrm{~V}$ to $300 \mathrm{~V}$. It can be seen from Figure 5 shows, with the rise of $\mathrm{V}_{\mathrm{G} 2}$, E1 began to appear current. Then the current tends to be stable. When G2 turn-off and G1 turn-on. The current in E1 reverse rise. It is much larger than the forward current. After calculation, compared with conventional IGBT trench type bidirectional IGBT in AC circuit turn-on time is $0.12 \mu$ s and turn-off time is 5.1ns. Its turn-on and turn-off loss have a great reduce. 


\section{Summary}

In this paper a new trench type bidirectional insulated gate bipolar transistor (IGBT) is proposed. We make a test in DC/AC circuits, and find conventional IGBT and new type IGBT Dynamic characteristics have a certain similarity. Through the analysis of trench type bidirectional IGBT in $\mathrm{DC} / \mathrm{AC}$ circuits simulation. The trench type bidirectional IGBT turn-on time is $0.5593 \mu \mathrm{s}$, off-time is $0.1127 \mu \mathrm{s}$. It shows that trench type bidirectional IGBT has a high turn-on and turn-off speed. Also the trench type bidirectional IGBT can accelerate the speed of carrier extraction, reduce the tail current and turn-off time.

\section{Acknowledgment}

* 1、 the National Natural Science Foundation of China (Grant no. 51177133)

2、 the Special Scientific Research Program of the Education Bureau of Shaanxi Province, China (Grant no. 2013JK1105).

\section{References}

[1] Qian Chen, Ming-zhi He,Trillion Q.Zheng (Beijing Jiaotong University,Beijing 100044,China);Datasheet Comparison and Selection of Different Types of IGBT[J];Power Electronics;2011-06

[2] K.D. Hobart, “Characterization of a Bi-Directional Double-Side Double-Gate IGBT Fabricated by Wafer Bonding”,ISPSD2010, pp.125-128.

[3] K.D. Hobart,“Transient Analysis of 3.3kV Double-Side Double-Gate IGBTs”,ISPSD2004, pp.273-276.

[4] Shanqi Zhao, Jolumy K. O. Sin, and ChVGuang Feng ,Design, Fabrication and Characterization of a Bi-direction Insulated Gate Bipolar Transistor, Department of Electrical and Electronic Engineering ,The Hong Kong University of Science and Teclmology,2004

[5] Shanqi Zhao,“Design, 1Fabrication and Characterization of a Bi-directional Insulated Gate Bipolar Transistor”,ICSICT2004,pp.332-335

[6] P. Z. He, L. B. Zheng, H. C. Fang, C. L. Wang, J. Hua, "Investigation of the Temperature Character of IGBT Failure Mode Based the 3-D Thermal-Electro Coupling FEM", Advanced Materials Research, Vols. 655-657, pp. 1576-1580, Jan. 2013

[7] Min ceng LIU (Information and Control Engineering School,Xi'an University of Architecture and Technology,Xi'an 710055,Shaanxi,China);Research of Driver and Protect of Cascaded Power Cell's IGBT[J];Electric Drive;2008-03

[8] Xi feng Guo, Da zhi Wang, Zhen Liu Wei,Han (Northeastern University,Shenyang 110819,China);Application and Performance Analysis of IGBT Driver Module of APF[J];Power Electronics;2012-09

[9] Jun Zhang 1, Qing Bian 2(1.Equiptment Department of China national heavy duty truck group Datong gear CO.,LTD.Datong 037005 China; 2.Technical Center of China national heavy duty truck group Datong gear CO.,LTD.Datong 037005 China);Design on Driving Circuit of Inverter based on IGBT[J];Techniques of Automation and Applications;2011-03

[10]Ming bao Chen (Hainan Industrial School Wuzhishan 572200 China);Research on Theoretic Model \& Its Package Types of the Bidirectional IGBT[J];Transactions of China Electrotechnical Society;2009-10 